\title{
A New Insight in the SMEs Internationalization Process
}

\author{
Eric Costa ${ }^{1,2}$, António Lucas Soares ${ }^{1,2}$ and Jorge Pinho de Sousa ${ }^{1,2}$ \\ ${ }^{1}$ INESC TEC - INESC Technology and Science, Campus da FEUP, Rua Dr. Roberto Frias \\ 378, 4200-465 Porto, Portugal \\ ${ }^{2}$ FEUP - Faculty of Engineering, University of Porto, Rua Dr. Roberto Frias S/N, 4200-465 \\ Porto, Portugal \\ eric.m.costa@inesctec.pt, als@fe.up.pt, jsousa@inescporto.pt
}

\begin{abstract}
There is growing evidence that internationalization of small and medium enterprises (SMEs) has become a priority to gain competitive advantage. However, SMEs still face major challenges and obstacles during these processes. This paper proposes a model of collaborative networks for internationalization processes of SMEs, mediated by industrial enterprise associations (IEAs), in order to improve decision-making processes. First, a systematic literature review (SLR) was performed to study the impact that networks and collaboration have in the decision-making process of internationalization. Then, the model was developed using adequate information and knowledge management tools. Finally, to understand the relevance of the proposed model, data were gathered through interviews to key persons in companies of the IT/electronics and textile industries. Results showed that collaborative networks can represent an important facilitator in the internationalization of SMEs and that IEAs can have a fundamental role for promoting collaboration in this domain, between associated SMEs.
\end{abstract}

Keywords: internationalization, collaborative networks, decision-making, systematic literature review, interviews.

\section{Introduction}

Small and medium enterprises (SMEs) are the backbone of the economy in most of the countries around the world, and they can significantly contribute to restoring growth by entering into new market opportunities provided by developed and emerging economies. There is growing evidence that internationalization of SMEs has become a key requirement to gain competitive advantage $[1,2]$. Some of the major motivations for going international are profit and growth goals, competitive pressures, foreign market opportunities, expansion opportunities, and domestic saturation [3-5]. However, SMEs still depend largely on their domestic markets and face challenges and obstacles during their internationalization processes. Among all difficulties in managing internationalization processes, SMEs face significant barriers related to the lack of capital, lack of adequate information and knowledge, and lack of adequate state support $[6,7]$.

Information and knowledge are seen as key resources for facilitating SMEs international expansion, reducing risk and uncertainty, and increasing creativity in 
decision-making [8]. From another perspective, it has been found that collaborative networks can represent an important facilitator in the internationalization of SMEs, particularly by nurturing knowledge sharing [9]. However, there is clearly a lack of comprehensive and systematic studies investigating how SMEs can access, organize and use the information generated in a collaborative network context, and how they can collaboratively convert this information into knowledge to support decisionmaking in internationalization processes.

This paper proposes a model of collaborative networks for internationalization processes of SMEs, designed to improve decisions in those processes and to increase their export propensity. A systematic literature review (SLR) was first performed to study the impact that networks and collaboration have in decision-making processes of SMEs internationalization. Then, from the results obtained with the SLR and following some suggestions for future research in the literature, the model of collaborative networks for internationalization was constructed. The main distinguishing factors of this approach are that the model considers Portuguese industrial enterprise associations (IEAs) as the context for collaboration and is based on state-of-the-art information and knowledge management models, to significantly improve collaborative decision making in internationalization processes. To have a first feeling on the relevance of the model, three interviews were performed with companies with experience in these processes.

This study contributes to the body of knowledge in internationalization by providing a new model for SMEs to undertake internationalization processes in collaborative networks. Based on the feedback from experienced companies, the authors believe that the model can bring significant benefits for SMEs to internationalize, benefiting from the valuable resources that networks can bring for the process, and somehow overcoming the barriers of lack of adequate information and knowledge in decision-making. Moreover this work will hopefully represent an additional opportunity for further research and discussion in international scientific meetings.

\section{Research Methodology}

The research methodology applied for this study was composed by three parts: (i) systematic literature review (SLR); (ii) model proposal; (iii) interviews.

\subsection{Systematic Literature Review}

A SLR was used to study the impact that networks and collaboration have in internationalization decision-making processes. The intention of using a SLR was to move away from traditional narrative or descriptive reviews of the literature, creating a basic framework for a more in-depth analysis of the literature by adopting a replicable, scientific and transparent process [10]. The underlying literature review methodology followed a five-step approach, as proposed by [11, 12]:

Step 1: Questions formulation. The research questions to be answered by this work were defined using the CIMO model [11] (Context, Intervention, Mechanisms, 
and Outcomes) and are the following: how do networks and collaboration influence the internationalization process of SMEs? how do networks and collaboration affect the decision-making process?

Step 2: Locating studies. Two databases were used: Web of Science and Scopus. These databases cover a significant proportion of the published material on internationalization, including the most relevant peer-reviewed journals on the area. The search criteria used was: (decision* OR "decision making" OR "decision-making”) AND (internationali*) AND (collaborat* OR "collaborative networks" OR network*)

Step 3: Study selection and evaluation. Inclusion and exclusion criteria were defined to select the studies to be included in the review. Only English and published peer-reviewed articles were included in the review. A 5-year time horizon was established (2010-2014) and some specific areas were considered, such as International Relations, Engineering, Operations Research, Business Management and Economics. After checking duplicates, titles and abstracts of the selected articles were analyzed for relevance. Articles eligible for review had to fulfil three main criteria: (i) articles had to be focused on SMEs and on the area of management studies; (ii) articles had to be empirical (qualitative and quantitative studies) rather than theoretical or conceptual; (iii) articles had to be focused on the influence of networks and collaboration in internationalization processes of SMEs, with specific emphasis on decision-making processes. The application of these criteria reduced the number of articles for analysis and synthesis to 16 (Table 1).

Table 1. Summary of the study selection and evaluation (date of search: March 2014)

\begin{tabular}{lccc}
\hline Criteria & Web of Science & Scopus & Total \\
\hline Database analysis & 180 & 195 & 375 \\
Date range & 91 & 99 & 190 \\
Document type & 72 & 75 & 147 \\
Subject area & 60 & 35 & 95 \\
Language & 58 & 34 & 92 \\
After checking duplicates & - & - & 81 \\
Title and abstract analysis & - & - & 16 \\
\hline
\end{tabular}

Step 4: Analysis and synthesis. The 16 papers obtained in this way were analyzed more in detail to extract and store information and cross tabulating the studies, in order to identify a set of key issues. For this purpose, a data extraction form in Excel was created.

Step 5: Reporting and using the results. Section 3 of this paper formally presents the SLR results.

\subsection{Model Proposal}

With the results of the SLR, and based on the future directions for research proposed in the literature and on the authors' knowledge and experience, a model is proposed in this paper (Section 4). This model is expected to support the internationalization processes of SMEs in collaborative networks contexts. The model is focused in IEAs addressed as collaborative networks for internationalization. SMEs operating in industrial sectors with more uncertain environments might have larger information 
requirements than other SMEs operating with less amounts of uncertainty [2]. Thus, two types of industrial sectors will be considered as the target for implementation of the model: (i) the IT and electronics industry that operates in a quite uncertain context; (ii) the textile industry where more certain and foreseen environments are expected.

\subsection{Interviews}

To understand the relevance of the proposed model and to validate the idea before starting to apply it in a real world context, some interviews were performed, this providing a first feedback from potentially interested companies.

Semi-structured interviews were carried out with three Portuguese companies (one from the IT/electronics industry and two from the textile industry) in order to discuss previous internationalization experiences and to evaluate the role of IEAs in those processes. Personnel with experience in internationalization processes were interviewed, with an average duration of each interview of approximately one hour. A semi-structured interview guide was used and all conversations were recorded and transcribed. The open-ended style of interview allowed the respondents to describe their experiences and ideas freely, without being limited to standardized categories [4]. Section 5 describes the main findings of the performed interviews.

\section{SLR Findings}

All the 16 analyzed papers had their focus on the influence of networks and collaboration in internationalization processes of SMEs. In fact, to limit the number of papers for analysis, emphasis was made on studies specifically approaching decisionmaking processes in internationalization.

The research methods most frequently adopted in the papers were interviews, questionnaires and surveys, with 13 of the 16 papers using those methods to obtain data for their studies. This kind of empirical research is very common in studies of internationalization: authors prepare different types of questions, and mainly approach companies' entrepreneurs, managers and key informants with experience in internationalization processes.

From the results of the SLR it can be concluded that, undoubtedly, SMEs need to form alliances, collaborate with different entities and use resources from their social and business networks, to be successful in internationalization processes. This conclusion can be generalized for almost all kind of companies from different types of industries or sectors: born global firms ${ }^{1}[3,13]$, manufacturing firms [14-16], service firms [17-19], and start-ups [20, 21]. According to this literature, an SME can establish collaborative networks for internationalization purposes with quite different types of intermediaries (Table 2).

1 "Born global firms" is a term used in the internationalization literature, applied to firms aiming for international markets right from their birth or very shortly thereafter $[3,13,20]$. 
Table 2. Types of intermediaries for collaborative networks in internationalization

\begin{tabular}{ll}
\hline Intermediaries & References \\
\hline Local partners (distributors, subcontractors and customers) & {$[3,6,13,15,17,19,20,8,22]$} \\
Competitors & {$[13,17,19,23]$} \\
Managers' contacts from previous jobs or experiences & {$[3,13,19,24]$} \\
External parties & {$[14,16]$} \\
Foreign firms & {$[13,18,19,21]$} \\
Institutional agencies & {$[8,25]$} \\
Consultants & {$[8]$} \\
Personal network, family and friends & {$[13,19,21,8,24,25]$} \\
Government bodies & {$[13,8]$} \\
Strategic allies and affiliated companies & {$[16,22]$} \\
\hline
\end{tabular}

The knowledge, experience, information and learning from business partners, network relationships and collaborations, are resources that can be very useful for making decisions in internationalization, and which have influence on first entries into markets and on selection of host countries. Table 3 presents the reasons for establishing collaborative networks in internationalization processes.

Table 3. Reasons for establishing collaborative networks in internationalization

\begin{tabular}{ll}
\hline Reasons & References \\
\hline Achieve rapid international expansion and growth & {$[3,13,17,19-21,8,22]$} \\
Obtain information about foreign markets & {$[14,16,19,20,8,25]$} \\
Explore how quickly an international opportunity can be exploited & {$[19,20,8]$} \\
Create strategic alliances or cooperation agreements & {$[13,20]$} \\
Provide access to new knowledge & {$[3,13-17,8]$} \\
Create a source of learning & {$[16,17,22,25]$} \\
Foster the decision to enter the export market & {$[13,16-19,8,22]$} \\
Build up a distribution and commercialization network abroad & {$[18]$} \\
Increase export propensity & {$[13,18,21,22]$} \\
Reduce information asymmetry & {$[8]$} \\
Reach target niches across international markets & {$[19]$} \\
Assist in mitigating the costs and risks of cross-border activities & {$[6,19,23]$} \\
Reduce uncertainty & {$[6,13,25]$} \\
Compensate the lack of financial resources & {$[13]$} \\
Assist in the selection of foreign entry modes & {$[3,6,13,19,8,22]$} \\
\hline
\end{tabular}

From the SLR results, it has been found that networks can represent an important facilitator in the internationalization of SMEs, in quite different ways such as: (i) providing important channels of information and knowledge to decision-makers; (ii) influencing the approach adopted by SMEs' leaders; (iii) influencing decisions on foreign market selection and entry mode; (iv) allowing to increase international commitment; (v) overcoming resource constraints. In despite of this, there is a lack of comprehensive and systematic studies investigating how SMEs can access, organize and use the information generated in a collaborative network context, and how they can collaboratively convert this information into knowledge to support decisionmaking in internationalization processes. This is in line with some findings and future directions for research, as proposed in the literature: 
- there is a lack of comprehensive and systematic studies investigating how SMEs can acquire and use information generated in a network context, to achieve higher levels of internationalization $[2,8]$;

- only limited studies show results on how SMEs can convert information into knowledge, for decision-making towards internationalization [26, 27];

- there has been a limited development of methods and techniques to improve the decision-making process of internationalization of SMEs [1];

- most of the literature on internationalization of SMEs is centered on companies acting in isolation, with only few studies considering collaborative internationalization processes [28].

\section{A Model of Collaborative Networks for Internationalization}

A model of collaborative networks for internationalization processes of SMEs is proposed in this paper, as a way to address some of the issues and future directions for research identified in the literature. The objective of creating this model was to contribute to the internationalization of SMEs, mainly in what concerns the associated decision-making processes. The general hypothesis is that information models and technologies, by providing information collected from heterogeneous sources and mediated by favorable collaborative contexts, positively influence the decisionmaking capabilities in the internationalization processes of SMEs. This paper is the first formal presentation of the model, providing a brief description of the approach and methods, as well as some of the expected impacts.

Introduction and Baseline Research. Managing effectively the information in internationalization decision processes is, for many companies, a critical success factor that has been addressed in the literature, in different ways and perspectives. It has in fact been shown that information is crucial for more rational decision-making [8], to manage international complexity and ambiguity [29], to reduce risks and uncertainty [26], and to stimulate awareness of foreign market opportunities [30]. There are also studies on the importance of the role of information in the creation of internationalization knowledge [17, 31], as well as on demonstrating that cooperation and networks are facilitators of internationalization [19, 32]. In spite of this, surprisingly there is a clear lack of exploratory studies on how state-of-the-art information management models and technologies can be used to improve collaborative decision-making in the internationalization of SMEs. Moreover, there is no sound reporting on the benefits of systematic networking and collaboration in internationalization.

Approach and Methods. The model was designed to be general, but it was instantiated and assessed by involving two Portuguese IEAs that contribute to the internationalization process of SMEs. IEAs can play a facilitating role to promote collaboration between SMEs, providing services and information to support the internationalization of their associates. The model will allow IEAs to assist SMEs in accessing and interpreting information, decide on the best internationalization strategy, and join competencies with other SMEs, to maximize the success of their 
internationalization processes. Actively involving IEAs in SMEs internationalization processes is, to the best of the authors' knowledge, an innovative contribution of the proposed model.

The model will encompass novel information management tools, in order to support collaborative internationalization decisions and processes. These information management models and technologies will allow SMEs to search, collect, integrate, organize and visualize information from different internet accessible, heterogeneous public and private sources, to be used and adapted in the different contexts where they are embedded. The concept of "information internalization" will be considered in the development of the solution. As information and knowledge are complementary and transformable, SMEs should find ways to transform information into knowledge in order to enhance the internationalization process. Information internalization is the process of absorbing both tacit and explicit information into the organization and translating it into knowledge, to be then applied with some specific purpose [33]. Therefore, in this model, a model will be developed in the context of firms acting in collaboration, exploring the following modes of information internalization: socialization, combination, externalization, and internalization [34].

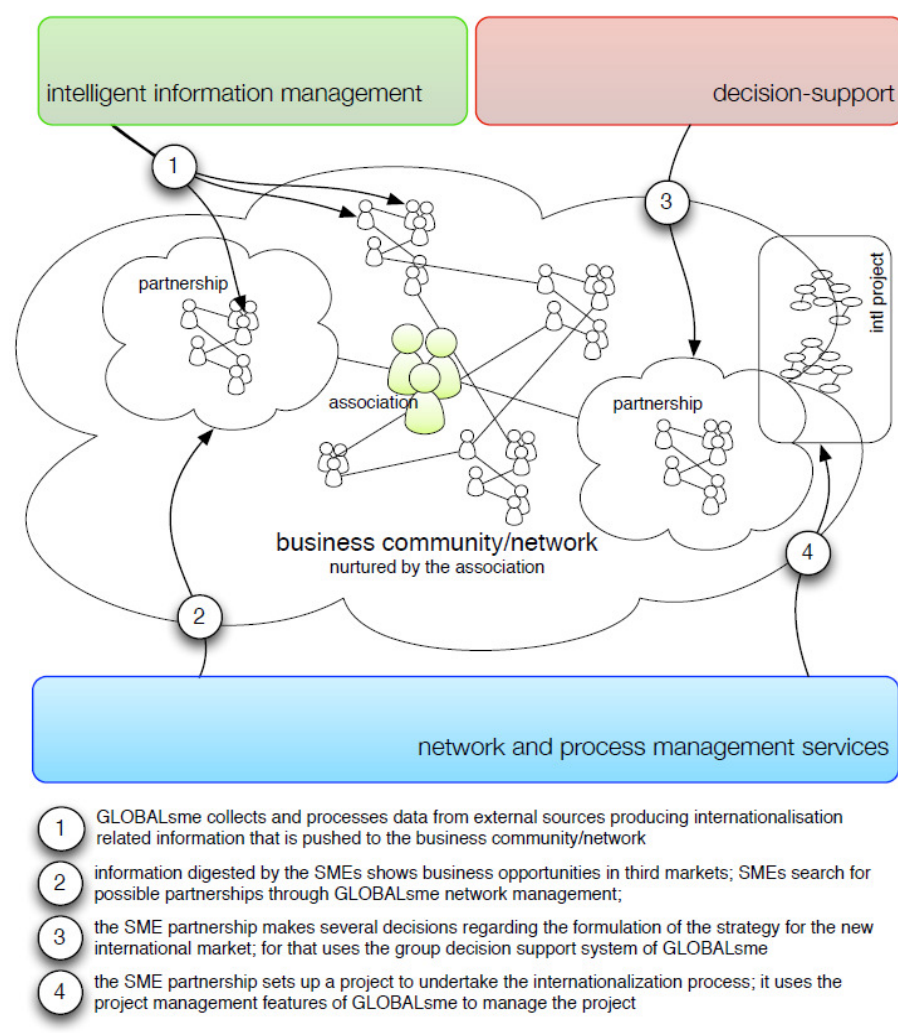

Fig. 1. Rationale of the proposed model 
Additionally, to improve the effectiveness of decision-making in the internationalization of SMEs, a collaborative decision support system (DSS) will be designed, based on multi-criteria decision-making approaches and on business intelligence. This DSS will support activities related to market selection, choice of partners and resources, assessment of risks and negotiation. The "business intelligence" concept will also be used for gathering, analyzing and distributing information, and also to support the strategic decision-making process [35]. Figure 1 presents the rationale of the model.

According to some future research directions identified by $[2,8,27]$, there is a need to explore how different contexts would result in different information and knowledge requirements for SMEs to internationalize. Dutot et al. [2] stated that SMEs in industries operating in more uncertain environments might have greater information requirements than SMEs in more "deterministic" environments. Therefore, to test and validate the model, the developed solutions will be applied to case studies addressing SMEs of two different types of industrial sectors: (i) the IT and electronics industry, which operates in a quite uncertain context; and (ii) the textile industry, where more certain and foreseen environments are expected.

The strength of the model depicted in Figure 1 lies in the combination of three valuable components for supporting enterprise networks: information, decisionmaking and collaboration. The rationale of the model use is a set of SMEs joining efforts through networks creation and collaborative process management services, to access high value added information and knowledge about internationalization conditions and to perform collaborative decision-making on the development of internationalization strategies. All these processes are facilitated by IEAs.

Expected Impacts. The main expected results and impacts of the model are:

- a description and explanation of the factors influencing the management of information that is relevant for internationalization purposes;

- a comprehensive characterization of the decision processes involved in the internationalization of SMEs and on how the IEA influences those processes;

- a description and explanation of the factors influencing the implementation of collaborative processes for internationalization;

- the identification and characterization of the information sources that contribute to market knowledge and experiential (network, cultural, entrepreneur) knowledge;

- an informational model adaptable to the processes of internationalization in collaboration, mediated by IEAs;

- an analytic solution for the adaptation of the informational model according to the type and mode of a specific internationalization process;

- a collaborative decision support model to explore the information model and the internationalization knowledge. 


\section{Interviews}

To understand the relevance of the proposed model, three interviews were performed with managers and persons responsible for internationalization decisions in companies from the IT/electronics industry and from the textile industry. The analysis of the interviews was divided in two parts: (i) the internationalization experience and the role of information and collaboration; (ii) the context provided by IEAs as collaborative networks.

Internationalization Experience and the Role of Information/Collaboration. All the interviewed companies have a lot of experience in internationalization processes. One of the interviewees stated that, to achieve a successful internationalization, the company should first gain experience and be well established in the home market, thus becoming ready for launching innovation products or services in foreign markets. All interviewees agreed that internationalization is a hard and expensive process, for which a company needs to be well prepared in advance. Financial capacity was therefore considered crucial since, at an initial stage, internationalization involves frequent travelling to the target countries, to analyze market conditions, understand legislation, and participate in fairs. Nevertheless, they pointed out internationalization as being essential for the growth of their companies.

Regarding the issue of sharing information with other companies or entities, the interviewees stated this is an interesting, viable and useful activity. They considered that companies might be willing to share information and knowledge about previous internationalization experiences, with companies wanting to start to internationalize in particular to markets where some experience has already been accumulated. This will provide a clear idea about the internationalization process, the problems and barriers to face, and all the particular aspects of some specific target countries.

In what concerns the involvement with other companies in collaborative networks, some believe that the collaboration of experienced companies with less experienced companies in internationalization projects, will increase their competitiveness, visibility and presence in the market. Moreover, as SMEs face more difficulties in internationalization processes, they could create joint ventures with each other to increase their chances of success. Yet, the interviewees of one of the companies suggested that, to collaborate, companies should be of equal size and have common interests, since companies with a different economic power will probably have different requirements and objectives, with different approaches, values and resources. They have also stated that in a process of internationalization, when approaching a new market, there should be a budget, a strategy and an outflow of resources to be adequately matched for companies to collaborate.

The Context of IEAs as Collaborative Networks. The three studied companies are associates of IEAs in their industrial sectors. All the companies agreed that IEAs should be more active in supporting their associates, as they can surely have an important role for the development of better internationalization processes. One interviewee considered that IEAs can act as disseminators of information and competences of their associates, thus promoting the creation of collaborations and of good synergies between companies. This would be particularly useful in launching 
internationalization processes together, as well as in exploring and creating new international opportunities.

One of the main problems faced by these companies is the lack of information and knowledge about certain markets. The interviewees consider that, in a first stage, IEAs may play an interesting role as "information aggregators", analyzing different markets and pointing paths to follow, and showing the reality of each market. At a later stage, IEAs may promote discussion and meetings between their associates, seeking the alignment of strategic objectives and the set-up of joint initiatives and investments in a given market, thus sharing costs and risks.

\section{Conclusion}

This study aims at contributing to the internationalization processes of SMEs, by presenting a new perspective on these processes and a new model of collaborative networks for internationalization. The next paragraphs present the main conclusions of the work, as well as some suggestions for further research possibly to be developed in future scientific meetings and conferences in this area.

From the results of the performed SLR, it has been found that collaborative networks can represent an important facilitator in the internationalization of SMEs, particularly by nurturing knowledge sharing, obtaining information about foreign markets and achieving rapid international expansion and growth.

From the responses obtained with the interviews, it is clear that IEAs might have a more active role in the internationalization processes of their associates. IEAs can have a fundamental role in fostering collaboration between associates, promoting both dissemination of opportunities and establishment of relationships.

The model proposed in this paper contributes to the scientific knowledge on SME internationalization by addressing how SMEs can establish collaborative networks for internationalization processes. It also contributes to the field of information and knowledge management, with the development of approaches and techniques to support these management activities for internationalization decision-making in collaborative networks. In this study the context used for collaboration is formed by Portuguese IEAs, which, to the best of the authors' knowledge, has never been addressed in previous research.

This paper shows that the management of internationalization is a research area that can be further explored with concepts and approaches based on topics of collaborative networks, and information and knowledge management. Researchers of these areas can bring new insights and contributions for the internationalization of SMEs, as well as for the internationalization of multinational enterprises (MNEs), with the creation of new business models and concepts [36-39] that, among other contributions, can provide an important support to internationalization.

Acknowledgments. This research was financed by the North Portugal Regional Operational Programme (ON.2 - O Novo Norte), under the National Strategic Reference Framework (NSRF), through the European Regional Development Fund (ERDF), and by national funds, through the Portuguese funding agency, Fundação 
para a Ciência e a Tecnologia (FCT), within project NORTE-07-0124-FEDER000057.

\section{References}

1. Schweizer, R.: The internationalization process of SMEs: A muddling-through process. J. Bus. Res. 65, 745-751 (2012)

2. Dutot, V., Bergeron, F., Raymond, L.: Information management for the internationalization of SMEs: An exploratory study based on a strategic alignment perspective. Int. J. Inf. Manage. 34, 672-681 (2014).

3. Andersson, S.: International entrepreneurship, born globals and the theory of effectuation. J. Small Bus. Enterp. Dev. 18, 627-643 (2011).

4. Hutchinson, K., Alexander, N., Quinn, B., Doherty, A.M.: Internationalization Motives and Facilitating Factors : Qualitative Evidence. 15, 96-122 (2007).

5. Kiss, A.N., Williams, D.W., Houghton, S.M.: Risk bias and the link between motivation and new venture post-entry international growth. Int. Bus. Rev. 22, 1068-1078 (2013).

6. London, K.: Multi-Market Industrial Organizational Economic Models for the Internationalization Process by Small and Medium Enterprise Construction Design Service Firms. Archit. Eng. Des. Manag. 6, 132-152 (2010).

7. Djordjevic, M., Sapic, S., Marinkovic, V.: How companies enter international markets: Presentation and analysis of the empirical research. Actual Probl. Econ. 7, 331-342 (2012).

8. Child, J., Hsieh, L.H.Y.: Decision mode, information and network attachment in the internationalization of SMEs: A configurational and contingency analysis. J. World Bus. 49, 598-610 (2014).

9. Musteen, M., Francis, J., Datta, D.K.: The influence of international networks on internationalization speed and performance: A study of Czech SMEs. J. World Bus. 45, 197-205 (2010).

10.Tranfield, D., Denyer, D., Smart, P.: Towards a Methodology for Developing EvidenceInformed Management Knowledge by Means of Systematic Review. Br. J. Manag. 14, $207-$ $222(2003)$

11.Denyer, D., Tranfield, D.: Producing a systematic review. Sage Handb. Organ. Res. Methods. (2009).

12.Wong, C., Skipworth, H., Godsell, J., Achimugu, N.: Towards a theory of supply chain alignment enablers: a systematic literature review. Supply Chain Manag. An Int. J. 17, 419437 (2012).

13.Kaur, S., Sandhu, M.S.: Internationalisation of born global firms: Evidence from Malaysia. J. Asia Pacific Econ. 19, 101-136 (2013).

14.Aspelund, A., Butsko, V.: Small and middle-sized enterprises' offshoring production: A study of firm decisions and consequences. Tijdschr. Voor Econ. En Soc. Geogr. 101, 262 275 (2010).

15.Hultman, J., Johnsen, T., Johnsen, R., Hertz, S.: An interaction approach to global sourcing: A case study of IKEA. J. Purch. Supply Manag. 18, 9-21 (2012).

16.Peng, Y.-S.Y.S., Yang, K.P.K.-P., Liang, C.C.C.-C.: The learning effect on business groups' subsequent foreign entry decisions into transitional economies. Asia Pacific Manag. Rev. $16,1-21(2011)$.

17.Casillas, J.C.J.C., Acedo, F.J., Barbero, J.L.J.L.: Learning, unlearning and internationalisation: Evidence from the pre-export phase. Int. J. Inf. Manage. 30, 162-173 (2010).

18.Castellacci, F.: Service Firms Heterogeneity, International Collaborations and Export Participation. J. Ind. Compet. Trade. 14, 259-285 (2014). 
19.Ibeh, K., Kasem, L.: The network perspective and the internationalization of small and medium sized software firms from Syria. Ind. Mark. Manag. 40, 358-367 (2011).

20.Cannone, G., Ughetto, E.: Born globals: A cross-country survey on high-tech start-ups. Int. Bus. Rev. 23, 272-283 (2014).

21.Kollmann, T., Christofor, J.: International entrepreneurship in the network economy: Internationalization propensity and the role of entrepreneurial orientation. J. Int. Entrep. 12, 43-66 (2014).

22.Torkkeli, L., Puumalainen, K., Saarenketo, S., Kuivalainen, O.: The effect of network competence and environmental hostility on the propensity of SMEs to internationalise. Emerald Group Publishing Limited, School of Business, Lappeenranta University of Technology, Lappeenranta, Finland (2011).

23.Malik, T.: First mover, strategic alliances and performance: context of turmoil in China. Chinese Manag. Stud. 6, 647-667 (2012).

24.Zucchella, A., Servais, P.: The internationalisation process of small- and medium-sized firms and the liability of complexity. Int. J. Entrep. Small Bus. 15, 191 (2012).

25.Santos-Alvarez, V., Garcia-Merino, T.: The role of the entrepreneur in identifying international expansion as a strategic opportunity. Int. J. Inf. Manage. 30, 512-520 (2010).

26.Nguyen, T.D., Barrett, N.J., Fletcher, R.: Information internalisation and internationalisation-Evidence from Vietnamese firms. Int. Bus. Rev. 15, 682-701 (2006).

27.Fletcher, M., Harris, S.: Knowledge acquisition for the internationalization of the smaller firm: Content and sources. Int. Bus. Rev. 21, 631-647 (2012).

28.Hong, P., Roh, J.: Internationalization, product development and performance outcomes: A comparative study of 10 countries. Res. Int. Bus. Financ. 23, 169-180 (2009).

29.Hsu, W.-T., Chen, H.-L., Cheng, C.-Y.: Internationalization and firm performance of SMEs: The moderating effects of CEO attributes. J. World Bus. 48, 1-12 (2013).

30.Zhou, L., Wu, W., Luo, X.: Internationalization and the performance of born-global SMEs: the mediating role of social networks. J. Int. Bus. Stud. 38, 673-690 (2007).

31.Saarenketo, S., Puumalainen, K., Kyläheiko, K., Kuivalainen, O.: Linking knowledge and internationalization in small and medium-sized enterprises in the ICT sector. Technovation. 28, 591-601 (2008).

32.Ciravegna, L., Lopez, L., Kundu, S.: Country of origin and network effects on internationalization: A comparative study of SMEs from an emerging and developed economy. J. Bus. Res. 67, 916-923 (2014).

33.Knight, G. a., Liesch, P.W.: Information internalisation in internationalising the firm. J. Bus. Res. 55, 981-995 (2002).

34.Nonaka, I., Takeuchi, H.: The knowledge-creating company: How Japanese companies create the dynamics of innovation. Oxford University Press, New York (1995).

35.Rouhani, S., Ghazanfari, M., Jafari, M.: Evaluation model of business intelligence for enterprise systems using fuzzy TOPSIS. Expert Syst. Appl. 39, 3764-3771 (2012).

36.Aguilera, C., castañeda, A., Guerrero, F.: Past, Present And Future Of The Andalusan Aeronautical Cluster. Network-Centric Collaboration and Supporting Frameworks SE - 61. pp. 583-590. Springer US (2006).

37.Imtiaz, A., Hauge, J.: Enriching Collaboration Among Eastern European SMEs Through Dedicated Virtual Platform. In: Camarinha-Matos, L. and Picard, W. (eds.) Pervasive Collaborative Networks SE - 58. pp. 567-576. Springer US (2008).

38.Jansson, K.: An Innovation and Engineering Maturity Model for Marine Industry Networks. In: Camarinha-Matos, L., Pereira-Klen, A., and Afsarmanesh, H. (eds.) Adaptation and Value Creating Collaborative Networks SE - 28. pp. 253-260. Springer Heidelberg (2011).

39.Jansson, K., Karvonen, I., Uoti, M.: Towards Collaborative Alignment of Engineering Networks. In: Camarinha-Matos, L., Xu, L., and Afsarmanesh, H. (eds.) Collaborative Networks in the Internet of Services SE - 47. pp. 467-474. Springer Heidelberg (2012). 